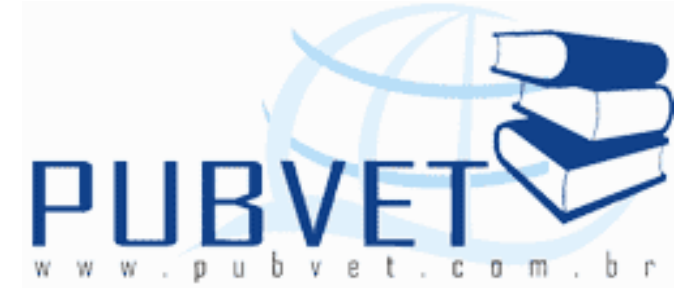

PUBVET, Publicações em Medicina Veterinária e Zootecnia.

\title{
Diagnóstico e controle da cinomose canina
}

\section{Fernanda Cassioli de Moraes $^{1}$, Carolina de Alvarenga Cruz ${ }^{1}$}

Raphaella Barbosa Meirelles-Bartoli ${ }^{2}$, Daniel Bartoli de Sousa ${ }^{2}$

${ }^{1}$ Alunas do Curso de Pós-Graduação em Medicina Veterinária, Faculdade de Ciências Agrárias e Veterinárias, UNESP, Campus Jaboticabal.

${ }^{2}$ Docentes do Curso de Medicina Veterinária da Universidade Federal de Goiás (UFG), Campus Jataí, Unidade Jatobá, Laboratório de Sanidade Animal.

\section{Resumo}

A cinomose é causada por um morbilivírus e acarreta uma doença viral multissistêmica, comprometendo vários tecidos e órgãos dos animais susceptíveis a essa infecção. Os sinais clínicos da doença englobam sinais respiratórios, secreções oculares e sinais nervosos, que acabam culminando na morte do animal. O diagnóstico do Vírus da Cinomose Canina (VCC) é difícil de ser feito e geralmente é realizado pela observação clínica, histórico (animal vacinado ou não), e podem ser utilizados exames confirmatórios, como histopatologia, isolamento viral, imunofluorescência direta/indireta, entre outros. Ultimamente o que tem sido mais executado é o $P C R$, demonstrando excelente sensibilidade. Quando a infecção é descoberta no início é possível pensar em cura, mas após atingir o sistema nervoso central, dificilmente 0 animal se recupera, e quando isso ocorre, apresenta déficits pelo resto da vida. Ainda não se conhece um tratamento específico para o combate do vírus da cinomose, mas, alguns tratamentos de apoio são realizados visando à 
MORAES, F.C. et al. Diagnóstico e controle da cinomose canina. PUBVET, Londrina, V. 7, N. 14, Ed. 237, Art. 1566, Julho, 2013.

melhoria na qualidade de vida do animal. Estudos recentes utilizando a acupuntura têm sido executados mostrando bons resultados e possibilitando esperança de um método mais eficaz de tratamento contra a cinomose.

Palavras-chave: cinomose, vírus da cinomose canina (VCC), morbilivírus

\section{Diagnosis and control of canine distemper}

\section{Abstract}

Canine distemper caused by a morbilivirus and causes multisystemic viradisease, affecting various tissues and organs of animals susceptible to this infection. The clinical signs of disease include respiratory signs, eye secretions and nerve signals, which eventually culminated in the death of the animal. The diagnosis of Canine Distemper Virus (CDV) is hard to do and is usually performed by clinical observation, history (vaccinated animal or not), and can be used confirmatory tests such as histopathology, virus isolatin, immunofluorescence direct / indirect, among others. Lately is has been over run is the PCR, demonstrating excellent sensitivity. When the infection is caught early it is possible to think of healing, but after reaching the central nervous system, hardly the animal recovers, and when this occurs, show deficits for life. Although there is no know specific treatment for combat distemper virus, but some treatments are performed in support aimed at improving the quality of life of the animal. Recent studies using acupuncture have been performed showing good results and hope of enabling a more effective method of treatment for distemper.

Keywords: canine distemper; canine distemper vírus (CDV); morbilivírus

\section{INTRODUÇÃO}

A cinomose é uma doença viral multissistêmica, altamente contagiosa e severa dos cães e de outros carnívoros, sendo observada mundialmente. 0 vírus da cinomose canina (VCC) é um morbilivírus da família Paramyxoviridae, e se relaciona proximamente com o vírus do sarampo; é instável no ambiente, 
MORAES, F.C. et al. Diagnóstico e controle da cinomose canina. PUBVET, Londrina, V. 7, N. 14, Ed. 237, Art. 1566, Julho, 2013.

sobrevivendo geralmente somente poucas horas e por não mais que alguns dias fora do hospedeiro, sendo destruído facilmente pelo ressecamento e pela maior parte dos desinfetantes (SHERDING, 2003).

O vírus é transmitido por meio de aerossóis e gotículas de secreções e excreções, produzidas pelo corpo de animais que estão enfermos. Um diagnóstico preciso é difícil, pois os sinais clínicos são variados e inespecíficos, podendo variar de acordo com a virulência da estirpe viral infectante, o estado imunológico e com a idade dos cães (REZENDE et.al., 2009). Não existe tratamento específico, utilizando-se uma terapia de suporte, de acordo com a sintomatologia desenvolvida (LITFALLA et al., 2008).

Não há predileção para sexo, idade ou raça, e em cães jovens e não vacinados, o acometimento do sistema nervoso central (SNC) é precedido de outros distúrbios como os respiratórios e os gastrointestinais. Os sinais neurológicos podem aparecer durante o acometimento sistêmico ou após a cura da manifestação inicial (GAMA, 2007).

Tradicionalmente a cinomose canina vem sendo diagnosticada por técnicas de isolamento viral, imunofluorescência e soroneutralização. Estas técnicas, entretanto, demandam demasiado tempo para análise e amostras com grande quantidade de partículas virais (POZZA et al., 2007).

Mais recentemente, a técnica da reação em cadeia pela polimerase precedida de transcrição reversa (RT- PCR) vem sendo empregada com sucesso na detecção do VCC em diferentes tipos de amostras biológicas provenientes de cães com sinais clínicos sistêmicos e neurológicos (GEBARA et al., 2004a).

Nos países em que a cinomose é endêmica, como no Brasil, milhares de cães morrem todos os anos. Muitos países têm encarado esta enfermidade como um risco econômico em potencial, por exemplo, a Finlândia, grande produtora de pele de animais como a raposa e o mink. Também é indispensável citar que a cinomose pode ser um dos fatores colaboradores da possível extinção de alguns animais selvagens, como ocorre em alguns 
MORAES, F.C. et al. Diagnóstico e controle da cinomose canina. PUBVET, Londrina, V. 7, N. 14, Ed. 237, Art. 1566, Julho, 2013.

parques africanos, uma vez que o vírus é altamente fatal para tais espécies (MARTINS; LOPES; FRANÇA, 2009).

No entanto, a escassez de estudos epidemiológicos e, consequentemente de informações sobre a ocorrência dessa infecção, dificulta a adoção de novos métodos de controle contra a doença. Desta forma, a cinomose canina começa a ser encarada com uma enfermidade emergente, e o seu entendimento tornase necessário para o aprimoramento de medidas que impeçam o avanço desta doença nas populações de canídeos, tanto domésticos quanto selvagens (MARTINS; LOPES; FRANÇA, 2009).

\section{DEFINIÇÃO}

A cinomose é uma doença viral severa e altamente contagiosa, que acomete cães e outros carnívoros de forma multissistêmica. Apesar de gerar diferentes alterações orgânicas, a gravidade do processo e a morte dos animais estão relacionadas às lesões desencadeadas pelo vírus no Sistema Nervoso Central (ORSINI; BONDAN, 2008).

Entre as doenças neurológicas que afetam os animais, a cinomose é considerada a causa mais comum de encefalite em cães, levando a uma alta taxa de mortalidade ou resultando em sequelas importantes que poderiam comprometer a qualidade de vida dos animais (GAMA et al., 2007).

\section{HISTÓRICO}

Os primeiros relatos sobre a cinomose canina datam de 1746 na América do Sul. Anos mais tarde, em meados de 1760 a doença foi descrita na Espanha, seguida de Inglaterra, Itália e Rússia. Um dado histórico interessante é que em 1763, cerca de 900 cães morreram em um único dia em Madri, e o óbito desses animais foi associado ao VCC. Somente em 1853, surgiu a teoria de que a cinomose dos cães poderia ter sido importada do Peru para a Europa, com entrada inicial feita por colonizadores espanhóis no século XVII (MARTINS; LOPES; FRANÇA, 2009). 
MORAES, F.C. et al. Diagnóstico e controle da cinomose canina. PUBVET, Londrina, V. 7, N. 14, Ed. 237, Art. 1566, Julho, 2013.

O agente causador da doença foi isolado pela primeira vez de um cão no início do século XX e demonstrado primeiramente por Carré, em 1905, por meio da inoculação de secreção nasal de cães infectados em cães jovens, desta forma reproduzindo experimentalmente a moléstia (MELLO et al, 2008). Logo depois, foi relatado em outros animais e ainda continua sendo descoberto em novas espécies (MARTINS; LOPES; FRANÇA, 2009).

Na primeira metade do século $X X$, a cinomose foi uma das doenças fatais mais comuns em cães no mundo. Posteriormente, a partir dos anos 60 e com o surgimento de vacinas específicas, este quadro modificou-se. No entanto, a mortalidade ainda é comum em animais não vacinados ou naqueles vacinados, em que se observa qualquer problema de falha vacinal (SILVA, 2004).

Pesquisas sobre cinomose, abrangendo aspectos como etiologia, epidemiologia, patogenia, patologia, imunologia e técnicas de diagnóstico são realizadas há mais de dois séculos, porém, estudos neuro-histopatológicos completos são escassos e antigos, pois foram realizados principalmente nas décadas de 1940 e 1950 (SILVA et al., 2009).

\section{ETIOLOGIA}

O VCC pertence à família Paramyxoviridae, gênero Morbillivirus. Trata-se de um RNA-vírus de fita simples, grande (150 a 350 nm), de simetria helicoidal, envelopado e antigenicamente relacionado aos vírus do sarampo e da peste bovina. Biótipos de cepas virulentas e atenuadas se diferenciam pela habilidade de replicação em várias culturas celulares de macrófagos, linfócitos e células epiteliais (BRAZ, 2009).

Morfologicamente, é constituído por seis proteínas estruturais - três internas $(L, N$ e $P$ ) e três inseridas no envelope $(M, H$ e $F)$. A proteína $N$ (nucleocapsídeo) é responsável pela proteção do material genético, enquanto as proteínas $\mathrm{L}$ e $\mathrm{P}$ (complexo polimerase) encontram-se envolvidas na transcrição e na replicação do RNA viral (ORSINI; BONDAN, 2008).

A proteína $M$ (matriz) é importante para a maturação viral e funciona como conectora das glicoproteínas de superfície ao nucleocapsídeo. As 
MORAES, F.C. et al. Diagnóstico e controle da cinomose canina. PUBVET, Londrina, V. 7, N. 14, Ed. 237, Art. 1566, Julho, 2013.

glicoproteínas $\mathrm{F}$ (fusão) e $\mathrm{H}$ (hemaglutinina) desempenham papéis importantes na patogenia da doença, sendo a $H$ responsável pela adsorção e a $F$, pela fusão do vírus à célula hospedeira. A proteína $\mathrm{H}$, por ser bastante variável, é a principal responsável pela diversidade antigênica observada nos vírus da cinomose, e está envolvida na indução da resposta imunológica do hospedeiro à infecção (ORSINI; BONDAN, 2008).

O VCC possui uma característica citopatogenicidade que é evidenciada pelo efeito citopático (ECP), tais como sincício, inclusão citoplasmática e intranuclear, arredondamento celular, citólise e apoptose. A replicação do vírus em células induz a formação de células gigantes com inclusões eosinofílicas intracitoplasmática e intranuclear. Essas inclusões surgem no citoplasma entre 24 e 48 horas PI, consistindo de uma massa de cobertura do nucleocapsídeo com material granular entremeado com sistema de túbulos e vesículas, semelhantes ao complexo de Golgi (BRAZ, 2009).

Após 48 horas da infecção, como mecanismo de defesa, esta estrutura sem as vesículas e com microvilos é expulsa da célula. Seguindo 60 horas há uma marcante formação das microvilosidades ocorrendo depois à fusão celular. Inclusões intranucleares eosinofílicas ocorrem depois da formação de sincício, que consiste de uma extensão rígida do nucleocapsídeo sem o material granular associada com a forma citoplasmática (BRAZ, 2009).

\section{EPIDEMIOLOGIA}

\subsection{Distribuição Geográfica}

A cinomose é de ocorrência mundial, porém, em vários países, devido à vacinação regular de grande parte da população canina, a frequência da doença clínica tem diminuído substancialmente, sendo relatados apenas focos esporádicos (NEGRÃO, 2006).

No Brasil a cinomose é endêmica e representa até $6 \%$ de todas as ocorrências clínicas e até $11 \%$ das mortes em cães (OLIVEIRA et al, 2009). Estima-se que, em nosso país, o grau de infecção seja significativamente maior que o grau de doença, e que acima de $50 \%$ das infecções em cães 
MORAES, F.C. et al. Diagnóstico e controle da cinomose canina. PUBVET, Londrina, V. 7, N. 14, Ed. 237, Art. 1566, Julho, 2013.

domésticos possam ser subclínicas. Filhotes e cães jovens são mais acometidos pela cinomose canina, contudo a faixa etária entre os três a seis meses apresenta maior número de casos (MARTINS; LOPES; FRANÇA, 2009).

Embora a cinomose possa ocorrer em qualquer época do ano, observa-se um maior acometimento dos cães durante os meses de inverno, devido, entre outros fatores, à sobrevivência do vírus no meio ambiente (MONTI, 2004).

\subsection{Cadeia Epidemiológica}

\subsubsection{Fonte de infecção}

Os animais infectados que desenvolve tanto a forma sintomática quanto a assintomática da cinomose são importantes na cadeia epidemiológica como fontes de infecção para os animais susceptíveis (NEGRÃO et al., 2007).

O cão é considerado o principal reservatório do vírus e a mais importante fonte de infecção da doença. Acredita-se que 25 a $75 \%$ dos animais susceptíveis desenvolvem infecção subclínica e eliminam o vírus no ambiente. (GEBARA et.al., 2004). Os animais silvestres infectados também representam fontes potenciais de infecção (MONTI, 2004).

As maiores oportunidades de disseminação da cinomose ocorrem em ambientes onde os cães são mantidos em grupos, como lojas de animais, abrigos, canis, clínicas veterinárias e colônias de pesquisas (SANTOS, 2006).

\subsubsection{Vias de eliminação}

Os animais acometidos expelem o agente nas excreções corporais, como urina, fezes, saliva, placenta e secreções respiratórias, podendo ou não apresentar sinais clínicos (MARTINS; LOPES; FRANÇA, 2009). Entretanto, o VCC sobrevive em exsudatos apenas por aproximadamente 20 minutos e é sensível à maioria dos desinfetantes hospitalares comuns (NELSON e COUTO, 2001). 
MORAES, F.C. et al. Diagnóstico e controle da cinomose canina. PUBVET, Londrina, V. 7, N. 14, Ed. 237, Art. 1566, Julho, 2013.

\subsubsection{Meios de transmissão}

A transmissão ocorre principalmente por aerossóis e gotículas infectantes provenientes de secreções e excreções oculares, respiratórias, digestivas e urinárias (HOSKINS, 2004). A transmissão transplacentária pode ocorrer em cães jovens (4 - 6 semanas de idade), mas não é comum (SHERDING, 2003).

A eliminação viral ocorre principalmente na fase aguda, de 1 a 2 semanas, entretanto, cães que apresentam sinais de infecção somente no SNC geralmente não estão eliminando o vírus para o meio ambiente (NELSON e COUTO, 2001).

\subsubsection{Porta de entrada}

A via de entrada mais comum é a respiratória, mas a infecção pode ocorrer pela via digestiva ou conjuntival, pelo contato direto. O VCC é uma estrutura muito delicada e é rapidamente inativado pelo calor e pela luz; a cápsula lipídica é sensível aos sais biliares e, como o vírus também é inativado pelo $\mathrm{pH}$ ácido, é incapaz de sobreviver à passagem pelo estômago e intestino delgado. Portanto, é pouco provável que a ingestão seja uma via de infecção importante (MONTI, 2004).

\subsubsection{Hospedeiros susceptíveis}

Diversas espécies de carnívoros domésticos e selvagens, tais como os da família Canidae (raposas, lobos, chacais e coiotes), Mustelidae (lontras, ferrets e furões), Procyoinidae (quatis e guaxinins) e alguns indivíduos da família Felidae (gatos domésticos e selvagens, leões e tigres) (ORSINI; BONDAN, 2008).

Os cães não imunizados de qualquer idade são susceptíveis, porém a doença é mais comum em filhotes com 3 a 6 meses de idade. Esta idade, na qual o cão torna-se susceptível à cinomose, é proporcional ao título de anticorpos de sua mãe e varia de acordo com a transferência passiva desses anticorpos pelo colostro (HOSKINS, 2004). 
MORAES, F.C. et al. Diagnóstico e controle da cinomose canina. PUBVET, Londrina, V. 7, N. 14, Ed. 237, Art. 1566, Julho, 2013.

Numa estimativa, acredita-se que quase a metade dos cães recémnascidos e/ou inadequadamente vacinados morre ao entrar em contato com o VCC pela primeira vez, por não apresentarem títulos adequados de anticorpos neutralizantes contra o vírus, sendo a outra metade resistente, tornando-se persistentemente infectados, podendo até apresentar a forma crônica da doença ao atingir a idade adulta (BORBA et al., 2002).

Não existe nenhuma comprovação epidemiológica que confirme predileção sexual, racial (BORBA et al., 2002) ou sazonal (SANTOS, 2006). Porém, cães sem raça definida são mais infectados pelo vírus da cinomose em comparação aos cães de raça. Isso ocorre pelo fato deste grupo ser extremamente representativo no Brasil (MARTINS; LOPES; FRANÇA, 2009), e porque os cães de rua geralmente apresentam maior chance de entrar em contato com partículas virais provenientes de outros cães já infectados (BORBA et al., 2002).

Porcos e gatos domésticos tem sido infectados somente de forma experimental, não sendo considerados grupos de risco. Já os ferrets são extremamente sensíveis ao VCC, podendo chegar a 100\% de morbidade e mortalidade (MARTINS; LOPES; FRANÇA, 2009).

O vírus da cinomose também tem causado doença em ambientes aquáticos, tanto de água doce quanto de águas marinhas. Na década de 800 vírus causou a morte de milhares de focas na Rússia (MONTI, 2004).

Animais selvagens reintroduzidos em áreas de soltura podem ser acometidos por doenças observadas na população de animais domésticos residentes nas proximidades. Isto ocorre em virtude da falta de adequação imunitária dos animais selvagens manejados frente aos patógenos naturalmente encontrados nas populações domésticas. Um exemplo desta situação foi recentemente observado na África oriental, quando grupos reintroduzidos de cachorros-selvagens-africanos (Lycaon pictus) apresentaram elevada mortalidade devido à cinomose transmitida por cães domiciliados na região adjacente à área de soltura (DIAS, 2008). 
MORAES, F.C. et al. Diagnóstico e controle da cinomose canina. PUBVET, Londrina, V. 7, N. 14, Ed. 237, Art. 1566, Julho, 2013.

O lobo guará apresenta susceptibilidade a diversos patógenos comuns aos animais domésticos. O primeiro registro de infecção pelo VCC nessa espécie foi feito no San Diego Zoological Gardens, em 1956, quando dois filhotes criados artificialmente por uma cadela lactante morreram com sinais clínicos sugestivos de cinomose canina. Em 1983, resultados satisfatórios foram obtidos na imunização de lobos guarás contra VCC com vacinas vírus vivo modificado (VVM) originário de cultura de fibroblastos de embrião de galinha (FEG) ou de ovos embrionados de aves SPF ("Specific Pathogen Free") (MAIA et al., 1999).

Não obstante, um acidente vacinal foi registrado quando VVM contra VCC originária de cultura de célula de rim de cão foi utilizada. No entanto, de acordo com o International Studbook for the Maned Wolf, VVM e/ou vacinas inativadas (VI) contra VCC vêm sendo frequentemente utilizadas na imunização de lobos guarás cativos (MAIA et al., 1999).

No Brasil, o Laboratório Solvay forneceu, durante alguns anos, doses de vacina contra VCC (VVM, monovalente, originária de cultura de FEG) aos zoológicos brasileiros para a vacinação de lobos guarás (MAIA et al., 1999).

Em racoons (Nyctereutes procyonoides) os surtos podem ter longa duração, aproximadamente três meses, o que facilita a disseminação viral e aumenta o número de mortes, chegando a $70 \%$ da população local, incluindo jovens e adultos. Em 1996, ocorreu um surto, em um parque nacional africano, de cinomose canina onde $85 \%$ dos leões apresentaram anticorpos contra o VCC, e $35 \%$ desses vieram a óbito. Ainda é importante destacar que a morbidade do surto espalhou-se para outros parques africanos, acometendo uma variedade ainda maior de animais (MARTINS; LOPES; FRANÇA, 2009).

A cinomose canina também é suspeita de ser a responsável por uma séria doença que vem acometendo os lobos do Alaska. Em cães o grau de mortalidade induzido pela cinomose canina só fica atrás dos números apresentados pela raiva dos cães, os índices vão desde $30 \%$ a $70 \%$. Podendo ainda, existir animais portadores principalmente no meio selvagem. Em estudo de soroneutralização (SN) realizado na Espanha, houve um alto grau de 
MORAES, F.C. et al. Diagnóstico e controle da cinomose canina. PUBVET, Londrina, V. 7, N. 14, Ed. 237, Art. 1566, Julho, 2013.

contato entre o VCC e a população de canídeos selvagens daquele país, perfazendo índices de prevalência de anticorpos que podem chegar a 24,3\% em lobos e 17,1\% em raposas (MARTINS; LOPES; FRANÇA, 2009).

Um grande surto de cinomose canina em grandes felinos ocorreu no outono de 1992, na Waysta Wildlife em San Fernando, Califórnia. Dezessete grandes gatos do mundo, incluindo leões, tigres, e leopardos, além de uma onça-pintada sucumbiram à doença apresentando sinais respiratórios, entéricos, e neurológicos. Esta foi a primeira vez que o VCC foi considerado o causador de um surto de tamanha proporção em grandes felinos. A cinomose foi diagnosticada por fluorescência, onde demonstrou-se a presença de anticorpos contra o antígeno VCC em dois leopardos que morreram em consequência da infecção (APPEL et.at., 1994).

Episódios recentes de surtos demonstram que pequenas populações de espécies ameaçadas podem se extinguir rapidamente quando afetadas pela cinomose canina. A taxa de mortalidade varia entre os táxons, podendo alcançar cerca de $80 \%$ em epidemias, dependendo da espécie e da imunocompetência dos hospedeiros. A enfermidade é um dos fatores que mais tem contribuído para o desaparecimento dos poucos exemplares de cães selvagens africanos (Lycaon pictus) que ainda restam (MARTINS; LOPES; FRANÇA, 2009).

\section{PATOGENIA}

O vírus da cinomose pode replicar-se em vários tipos celulares, mas as células linfóides e os macrófagos parecem ser particularmente susceptíveis. Ao infectar essas células, o vírus se dissemina para os órgãos linfoides como baço, timo, linfonodos e medula óssea, onde infecta os linfócitos maduros promovendo a apoptose e consequentemente queda da imunidade (BARBOSA et al., 2011).

A maior parte dos cães é provavelmente infectada pela inalação do vírus e os primeiros locais de atividade viral são as tonsilas palatinas e os linfonodos brônquicos. De lá, o vírus atinge a corrente sanguínea em aproximadamente 
MORAES, F.C. et al. Diagnóstico e controle da cinomose canina. PUBVET, Londrina, V. 7, N. 14, Ed. 237, Art. 1566, Julho, 2013.

dois dias, provavelmente conduzidos por macrófagos, passando pelos vasos linfáticos (BRAZ, 2009).

Após o transporte por células mononucleares circulantes, o vírus é encontrado multiplicando-se na medula óssea, baço e outros tecidos linfóides uma semana após a infecção. A multiplicação do vírus nessas áreas é responsável pela linfocitólise e pela leucopenia, características da doença. Subsequentemente, conduzidos por células mononucleares migrantes, os vírus começam a aparecer em estruturas epiteliais em todo o corpo e, depois de um período de multiplicação nesses locais, geralmente de poucas semanas, os sinais clínicos referentes às lesões epiteliais começam a aparecer (BRAZ, 2009).

Uma viremia na primeira semana pós-infecção coincide com a proliferação viral nos órgãos linfóides associada à leucopenia por linfopenia, como consequentes danos às células linfóides B e T. No quinto e sexto dia pósinfecção (PI), se espalha para o pulmão e lâmina própria da nasofaringe e mucosa conjuntival. Uma segunda viremia, com vírus associado à célula e fase plasmática pode ocorrer entre o oitavo ao décimo quarto dia PI, sendo que algumas vezes podem ser observadas até o vigésimo quarto dia PI. O estágio virêmico pode durar até seis semanas (BRAZ, 2009).

$O$ vírus pode ser encontrado no cérebro, no mínimo após 8 a 10 dias da primeira exposição, mas em geral ocorrem algumas semanas até os sinais nervosos começarem a aparecer. O grau de envolvimento epitelial e nervoso varia de animal para animal. Em alguns casos ele é mínimo, enquanto em outros ocorrem doenças respiratórias graves, gastroenterite, conjuntivite, hiperqueratose e encefalite. Não se sabe exatamente como essa difusão do vírus para o SNC ocorre, mas acredita-se que a invasão ocorra via hematógena em associação a linfócitos e monócitos infectados que atravessam a barreira hematoencefálica (SILVA, 2009).

Alguns pesquisadores defendem a ideia de que provavelmente em todos os casos de cinomose, o vírus atinge o SNC, mesmo nos casos em que os cães não manifestam sinais neurológicos. Nos casos em que os sinais sistêmicos 
MORAES, F.C. et al. Diagnóstico e controle da cinomose canina. PUBVET, Londrina, V. 7, N. 14, Ed. 237, Art. 1566, Julho, 2013.

progridem para manifestação neurológica, provavelmente ocorre falha da resposta imune do hospedeiro em eliminar o vírus que invadiu o cérebro (SILVA, 2009).

Quando isso ocorre, a encefalite é uma causa comum de morte em animais acometidos. A desmielinização multifocal é uma característica constante na fase aguda de infecção e é induzida pela presença do vírus em células nervosas. $O$ fator relacionado ao vírus inclui mudanças conformacionais nas proteínas virais $\mathrm{N}$ e $\mathrm{M}$ após interação com diferentes determinantes moleculares ou a proteína viral $\mathrm{H}$ das amostras neurovirulentas, as quais são mais eficientes em mediar à infecção em neurônios, o que ocorre provavelmente devido a sua maior afinidade pelos receptores destas células (BRAZ, 2009).

A encefalite aguda pelo VCC, que ocorre no início da infecção em cães jovens ou animais imunossuprimidos, é caracterizada pela replicação viral direta e injúria, causando lesões multifocais na massa branca e cinzenta, geralmente acompanhada de sinais clínicos sistêmicos. No caso de uma encefalite crônica pelo VCC, ocorre um processo imunopatológico vírus independente, que afeta predominantemente as células dendríticas, onde a reação do sistema imune é o mecanismo patogênico da desmielinização (autoimune), e com frequência, não manifesta sinais clínicos sistêmicos (BRAZ, 2009).

Se uma resposta imune ocorrer rapidamente, o vírus pode ser eliminado antes que ele tenha a chance de penetrar no cérebro. À medida que a doença progride e o cão desenvolve algum grau de imunidade, o vírus vai sendo eliminado primeiro dos tecidos linfóides e da região cerebral, onde os anticorpos circulantes não podem penetrar. Eventualmente o vírus pode ser eliminado de todos os tecidos, mas pode persistir por períodos mais longos no SNC. Esta persistência do vírus pode contribuir para o desenvolvimento de sinais nervosos num cão, muito tempo depois (algumas vezes depois de muitos meses) de ele ter se recuperado dos efeitos sistêmicos do vírus (BRAZ, 2009). 
MORAES, F.C. et al. Diagnóstico e controle da cinomose canina. PUBVET, Londrina, V. 7, N. 14, Ed. 237, Art. 1566, Julho, 2013.

\section{SINAIS CLÍNICOS}

O período de incubação dura cerca de uma semana, mas pode estenderse por quatro semanas ou mais, quando os sinais nervosos aparecem sem evidência prévia (QUINN et al., 2005).

A gravidade e a duração da doença são variáveis e influenciadas pela estirpe do vírus infectante, pela idade e estado imunológico do animal infectado e pela rapidez da resposta imunológica à infecção (QUINN et al., 2005). Sendo assim, animais previamente imunizados podem vencer o vírus ainda no território linfóide, evitando a invasão para outros órgãos (GAMA et al., 2005).

Os sinais clínicos são multissistêmicos e extremamente variáveis, geralmente a depressão e anorexia são seguidas por vômito e diarreia, que pode ser mucosanguinolenta (MONTI, 2004).

Outros sinais comuns são conjuntivite serosa a mucopurulenta e tosse seca, que passa a ser produtiva dentro de poucos dias (MONTI, 2004). Alterações oculares também são comumente associadas com a infeç̧ão pelo vírus da cinomose, como: uveíte anterior, neurite óptica (com consequente cegueira e pupilas dilatadas) e retinocoroidite. A ceratoconjuntivite seca e cicatrizes retinais hiper-reflexivas, chamadas lesões em medalhões são observadas em alguns cães com infecção crônica (NELSON e COUTO, 2001).

Manifestações clínicas menos comuns, como a hipoplasia do esmalte dentário, pode ocorrer em animais jovens, antes do desenvolvimento da dentição permanente (LITFALLA et al., 2008).

Acredita-se que metade dos cães acometidos tem sinais sistêmicos antes ou concomitantemente aos neurológicos, e que aproximadamente metade dos sobreviventes aos sinais sistêmicos, apresentam mais tarde, sequelas neurológicas da cinomose (MONTI, 2004).

Os sinais neurológicos mais comumente observados sâo: cegueira, convulsões, ataxias cerebelar, vestibular ou sensorial e mioclonias. Estas mioclonias são contrações repetitivas e involuntárias de um músculo ou de um ou mais grupos musculares (principalmente os músculos da mastigação e 
MORAES, F.C. et al. Diagnóstico e controle da cinomose canina. PUBVET, Londrina, V. 7, N. 14, Ed. 237, Art. 1566, Julho, 2013.

apendiculares) que estão presentes em 40 a 75\% dos casos de cinomose e já foram consideradas como sendo patognomônicas da cinomose, porém podem ocorrer em outras doenças. (MONTI, 2004).

Se houver uma resposta imunológica rápida e efetiva, a infecção será subclínica com recuperação completa e eliminação do vírus sem enfermidade clínica. Isso ocorre por volta do $14^{\circ}$ dia pós-infecção. Caso a resposta imunológica seja lenta ou parcial, os sinais clínicos multissistêmicos podem não acontecer, mas a localização no SNC poderá resultar em encefalomielite crônica com retardo do início dos sinais neurológicos (LITFALLA et al., 2008).

Em alguns animais, o VCC persiste nos tecidos nervosos e ocasiona uma encefalite tardia, chamada encefalite do cão idoso, que se assemelha à panencefalite esclerosante subaguda desenvolvida em humanos adultos infectados na infância pelo vírus do sarampo. As lesões do SNC são as alterações mais graves da doença, e geralmente culminam com o óbito dos animais (ORSINI; BONDAN, 2008).

\section{DIAGNÓSTICO}

O diagnóstico clínico, realizado com base no exame físico, anamnese e por exames complementares, às vezes, é inconclusivo, pois o mesmo padrão também pode ser encontrado em outras doenças infecciosas e parasitárias de cães (BARBOSA et al., 2008).

O VCC pode estar presente em uma gama de amostras biológicas e nos diferentes estágios da infecção, a urina, o sangue total, os leucócitos, as fezes, a saliva, as secreções respiratórias e o líquor podem apresentar o vírus em títulos variados (NEGRÃO et al., 2007).

O emprego de um método sensível de diagnóstico ante mortem do VCC permite que condutas adequadas de tratamento e profilaxia, tanto da cinomose canina quanto de outras enfermidades que apresentam sinais clínicos semelhantes, possam ser adotadas com antecipação e eficiência (GEBARA et al., 2004). 
MORAES, F.C. et al. Diagnóstico e controle da cinomose canina. PUBVET, Londrina, V. 7, N. 14, Ed. 237, Art. 1566, Julho, 2013.

\subsection{Colheita de material para análise}

Nos estágios iniciais da doença (isto é, 2 a 3 semanas após a infecção), a colheita de esfregaços da camada amarelada do sangue coagulado, de raspados, das tonsilas ou de conjuntiva, secos ao ar, pode ser usada para testes de imunofluorescência para o antígeno do vírus da cinomose, ou para a demonstração histológica de corpúsculos de inclusão. No entanto, com a progressão da doença o sucesso destes testes dimuniu. Com isso pode-se utilizar culturas de macrófagos alveolares de cão, por serem muito mais susceptíveis ao vírus da cinomose para o isolamento do vírus. Dos últimos, a mucosa respiratória e a da bexiga, assim como a urina são particularmente propícias para o achado de inclusões no auge da doença (THOMPSON; SUTTON; CHANDLER, 1989).

\subsection{Diagnóstico laboratorial}

O diagnóstico clínico pode ser confirmado pela identificação de corpúsculos de inclusão (Corpúscolos de Lentz), característicos da doença, em células associadas à exsudato, nas células epiteliais e em neutrófilos, porém sua ausência não exclui a infecção pelo VCC (GEBARA et.al., 2004a).

As alterações laboratoriais dos cães portadores do VCC normalmente consistem de uma leucopenia, quatro a seis dias após a infecção (BARBOSA et al., 2011). A anemia, segundo Silva et al., (2004) pode ser atribuída ao aumento da destruição dos eritrócitos, determinada pela presença do vírus ou pela deposição de imunocomplexos na membra eritrocitária, ou pela diminuição de sua produção, que pode estar associada ao estresse desencadeado pela doença que leva a uma falência medular.

A linfopenia, a monocitose e a neutrofilia ocorrerão quando o quadro já estiver instalado, e geralmente, a leucocitose é resultante de infecção bacteriana secundaria (BARBOSA et al., 2011). Gebara et al., (2004a) em seus estudos observaram que a leucocitose foi a alteração hematológica mais frequente nos grupos de cães com sinais clínicos da cinomose. 
MORAES, F.C. et al. Diagnóstico e controle da cinomose canina. PUBVET, Londrina, V. 7, N. 14, Ed. 237, Art. 1566, Julho, 2013.

A trombocitopenia também foi um achado frequente nos animais estudados por Silva et al. (2004). Segundo os autores, apesar dos mecanismo responsável pela trombocitopenia associada a infecções virais ser pouco conhecida na veterinária, sabe-se que para o gênero Morbillivirus observa-se um aumento de anticorpos antiplaquetários e que a trombocitopenia se deva, provavelmente, a uma resposta imunomediada com remoção das plaquetas pelo sistema reticulo endotelial.

Outros estudos realizados avaliaram o quadro hematológico de cães com cinomose e verificaram que, nem sempre há alteração no quadro, e quando há, não são especificas da doença (BARBOSA et al., 2011). Sabe-se também que a resposta hematológica varia de um individuo para outro, assim como a fase da infecção viral (SILVA et al., 2004).

Gebara et.al. (2004a) fazem uma analogia com os resultados obtidos e conclui que os dados hematológicos não são suficientes para a realização de diagnóstico diferencial, uma vez que eles podem ser influenciados por fatores tais como a estirpe viral infectante, a fase de replicação do vírus no momento da colheita do sangue e a presença ou não de infecção bacteriana secundária.

A diminuição da ingestão proteica bem como o comprometimento intestinal são fatores determinantes na redução dos níveis séricos da albumina, o que justificaria a hipoproteinemia observada na maioria dos animais com cinomose (SILVA et al., 2004).

Assim, é necessário um diagnóstico mais preciso para a cinomose canina, e este pode ser realizado por métodos diretos, tais como, isolamento, histopatolologia, imunohistoquímica, imunofluorescência direta, métodos moleculares e indiretos como ELISA, imunofluorescência indireta, soroneutralização e outros (BRAZ, 2009). 
MORAES, F.C. et al. Diagnóstico e controle da cinomose canina. PUBVET, Londrina, V. 7, N. 14, Ed. 237, Art. 1566, Julho, 2013.

\subsection{Exames diretos}

\subsubsection{Isolamento viral}

O isolamento pode ser realizado por meio da inoculação de amostras clínicas (secreção nasal, ocular e sangue) em células de linhagem. Os efeitos citopáticos observados são: lise celular, arredondamento celular, descolamento da monocamada, formação de sincício. A monocamada pode ser corada com cristal violeta e corpúsculos de inclusão podem ser vistos tanto intranuclear como intracitoplasmático (BRAZ, 2009).

\subsubsection{Diagnóstico molecular}

Métodos moleculares, como Reação em Cadeia da Polimerase (RT$\mathrm{PCR}$ ) têm contribuído para o diagnóstico de cinomose. Amostras como sangue, urina, soro, secreção nasal ou ocular e fragmentos de órgãos podem ser utilizados para a detecção do VCC (BRAZ, 2009).

Essa vem sendo empregada com sucesso na detecção do VCC em diferentes tipos de amostras biológicas provenientes de cães com sinais clínicos sistêmicos e neurológicos, e as principais vantagens incluem a rapidez na obtenção dos resultados, a não exigência da infecciosidade da partícula viral e os altos níveis de especificidade e sensibilidade, além de ser possível utilizar diferentes tipos de amostras biológicas, como sangue, soro, urina e fragmentos de órgão (GEBARA et al., 2004a).

\subsubsection{Histopatologia}

O VCC produz corpúsculos de inclusão chamados de corpúsculos de Lentz intracitoplasmáticos ou intranucleares em diversos tecidos que podem ser visualizados após coloração pelos métodos de Sellers, Shorr ou Giemsa. Histologicamente as inclusões são compostas por agregados de nucleocapsídeos e restos celulares resultantes da ação vírica (BRAZ, 2009).

$\mathrm{Na}$ microscopia, os corpúsculos de inclusão apresentam-se intracitoplasmático e/ou intranucleares e podem ser observados no estômago, na bexiga urinária, no SNC, na pelve renal, na conjuntiva e nos 
MORAES, F.C. et al. Diagnóstico e controle da cinomose canina. PUBVET, Londrina, V. 7, N. 14, Ed. 237, Art. 1566, Julho, 2013.

coxins digitais. Nos pulmões, estes corpúsculos são encontrados no epitélio de brônquios e bronquíolos e em macrófagos. Também podem ser encontrados em baço, linfonodos e tonsilas (SONNE, 2008).

Além da presença de corpúsculos de inclusão e alterações linfóides, o diagnóstico histopatológico é baseado nas alterações catarrais e purulentas por todo o trato respiratório, com bronquiolite e metaplasia epitelial nos pulmões (THOMPSON; SUTTON; CHANDLER, 1989).

O exame histológico do cérebro de filhotes que sofrem de cinomose generalizada mostra desmielinização e malácia, particularmente na ponte, medula e folhas cerebelares (THOMPSON; SUTTON; CHANDLER, 1989).

\subsubsection{Imunohistoquímica}

O diagnóstico da cinomose canina pela técnica de imunohistoquímica pode ser realizado ante-morte utilizando mucosa nasal, epitélio dos coxins e pele (tecido do pescoço dorsal), ou pós-morte a partir de tecidos do baço, tonsilas, linfonodos, estômago, pulmão, duodeno, bexiga e cérebro. Os resultados são mais satisfatórios na fase aguda da infecção (BRAZ, 2009).

\subsubsection{Imunofluorescência}

A imunofluorescência pode ser executada em duas formas: Imunofluorescência direta (IFD) e imunofluorescência indireta (IFI). No procedimento direto o anticorpo anti-cinomose é marcado com corante isoticionato de fluoresceína (ITFC). No método indireto, o teste é realizado em duas etapas, na primeira introduz o anticorpo anti-cinomose não marcado, na segunda etapa um anticorpo anti-imunoglobulina é adicionado (BRAZ,2009).

Esta técnica é aplicada ao diagnóstico de cinomose canina desde o primórdio da descoberta do vírus, e tem sido a técnica de escolha para o diagnóstico laboratorial da enfermidade (BRAZ,2009).

Várias amostras clínicas podem ser utilizadas na IFD, como esfregaço nasal, conjuntival, sanguíneo e impressão de genital. No sangue o vírus pode ser revelado a partir do terceiro, quarto dia pós-infecção indo até o $17^{\circ}$ dia, 
MORAES, F.C. et al. Diagnóstico e controle da cinomose canina. PUBVET, Londrina, V. 7, N. 14, Ed. 237, Art. 1566, Julho, 2013.

sendo detectados dois dias antes do pico febril. Em esfregaço conjuntival o vírus pode ser observado a partir do nono dia PI, sendo que neste substrato a detecção depende do quadro febril ou se o animal esta na fase aguda ou crônica. Mas os esfregaços conjuntivais tendem a serem positivos intermitentes, enquanto o sangue é consistentemente positivo. Células da mucosa genital foram positivas no quinto dia (infecção experimental via intracranial e intravenosa) e do sétimo ao $10^{\circ}$ dia (oronasal) (BRAZ, 2009).

\subsection{Exames indiretos}

As técnicas sorológicas apresentam valor diagnóstico limitado para o VCC uma vez que os animais que morrem por cinomose podem ou não apresentar títulos mensuráveis de anticorpos (GEBARA, et.al., 2004a), Também existe a possibilidade de que os altos títulos de anticorpos possam ser resultantes de vacinação prévia, assim como infecção clínica ou subclínica anteriores e os baixos títulos podem ser decorrentes às propriedades imunossupressoras do VCC (SANTOS, 2006).

Dentre os testes sorológicos empregados no diagnóstico da cinomose estão os ensaios imunoenzimático (ELISA), fixação de complemento, soroneutralização, imunoperoxidase, imunofluorescência indireta e imunocromatografia (BRAZ, 2009).

\section{ACHADOS ANATOMOPATOLÓGICOS}

Os cães infectados podem apresentar secreções nasais e oculares serosas, catarrais ou mucopurulentas. Na necropsia, as alterações macroscópicas são variáveis e geralmente inconclusivas, mesmo nos cães que apresentam sinais clínicos graves. A atrofia do timo, considerada por alguns patognomônica da cinomose, não é um achado consistente, particularmente nos casos leves (SONNE, 2008)

Apesar de os pulmões estarem com aspecto normal, frequentemente várias alterações ocorrem, desde edema pulmonar difuso até áreas escuras de broncopneumonia bacteriana secundária, ou lesões cinza-amareladas 
MORAES, F.C. et al. Diagnóstico e controle da cinomose canina. PUBVET, Londrina, V. 7, N. 14, Ed. 237, Art. 1566, Julho, 2013.

proeminentes de hiperplasia do epitélio alveolar, afetando primeiramente lobo apical e intermédio. Os linfonodos podem estar congestos ou hemorrágicos (SONNE, 2008) e os coxins podais podem apresentar-se com tumefações duras e escamosas (HOSKINS, 2004).

Os pulmões que apresentarem uma pneumonia intersticial serão caracterizados por infiltrado de células mononucleares, com presença de macrófagos espumosos, hiperplasia de pneumócitos e edema alveolar. No intestino pode-se observar degeneração do epitélio, necrose linfóide e infiltração de linfócitos na lâmina própria (SONNE, 2008).

Alterações macroscópicas do SNC são pouco frequentes, mas quando estão presentes nota-se hiperemia das leptomeninges, excesso de líquido cefalorraquidiano e, algumas vezes, dilatação ventricular. Malácia e cavitação da substância branca podem ocorrer em alguns casos de lesão inflamatória crônica ou processo de desmielinização acentuada (SILVA, 2009). Também pode apresentar lesões principalmente no cerebelo e nas colunas brancas da medula espinhal, caracterizadas por áreas de necrose bem delimitadas, desmielinização e inclusões intranucleares principalmente em astrócitos (MELLO et al., 2008).

A desmielinização é um processo que ocorre no SNC e sempre está presente quando o órgão é acometido pelo vírus. Pode ocorrer de duas maneiras, de acordo com a evolução da doença: fase aguda, em que não há inflamação e a fase crônica na qual a inflamação está frequentemente presente (SILVA, 2009).

Cães infectados pelo VCC antes da erupção dos dentes permanentes podem apresentar hipoplasia do esmalte dentário, com consequente exposição da dentina que é demonstrado macroscopicamente por áreas de coloração amarelo/bege (SONNE, 2008)

Gebara et al (2004b) citam em seu trabalho os achados histopatológicos em cérebro e cerebelo de cães com diagnóstico positivo para o VCC, realizado pela técnica da RT-PCR. Dez cães distribuídos em dois grupos ( $A$ e $B$ ), de acordo com a faixa etária. O exame histopatológico 
MORAES, F.C. et al. Diagnóstico e controle da cinomose canina. PUBVET, Londrina, V. 7, N. 14, Ed. 237, Art. 1566, Julho, 2013.

revelou encefalite desmielinizante multifocal aguda e crônica grave e com necrose da substância branca. Em nove cães positivos na RT-PCR para o VCC, foram observado processos de astrogliose e astrocitose no cérebro e cerebelo.

Em estudo realizado por Sonne et.al., em 2008, efetuando necropsia em 760 caninos, a cinomose foi diagnosticada em 63 desses animais através do exame macroscópico e microscópico. Os achados macroscópicos encontrados no exame externo dos cães necropsiados foram corrimento ocular e nasal mucopurulentas (27/54), hiperqueratose dos coxins digitais (19/54), pústulas abdominais (12/54) e secreção ceruminosa no conduto auditivo externo (31/54). Os pulmões se mostravam não colabados, edemaciados e avermelhados em 51 cães. O estômago apresentava mucosa hiperêmica em 19 cães e em 8 destes evidenciavam-se pequenas erosões da mucosa gástrica (SONNE, et.al.,2009).

Foi observado pelos mesmos autores, no intestino delgado dos cães hiperemia da mucosa (19/54) e proeminência das placas de Peyer (22/54). Em alguns cães havia conteúdo diarréico amarelo ou avermelhado no intestino. Em oito cães $(14,8 \%)$ infestações discretas por Toxocara sp., Ancylostoma sp. e/ou Trichuris sp. foram encontradas no intestino. Havia atrofia do timo em 19 cães $(35,2 \%)$ e os linfonodos mesentéricos estavam aumentados de volume em 16 cães (29,6\%). Em um cão observou-se placas fibrinonecróticas no dorso da língua e no palato, secreção ceruminosa no conduto auditivo e numerosas pústulas abdominais. Emdois cães, um da raça Beagle de 3 meses de idade e outro da raça Shih-tzu de 2 meses, observou-se hidrocefalia (SONNE, et.al.,2009).

Pneumonia intersticial foi observada em 44,4\% (24/54) dos cães, em $18,5 \%$ dos casos (10/54) a pneumonia broncointersticial e em 18,5\% (10/54) broncopneumonia supurativa. Em alguns cães (9/54), observaram-se células sinciciais no pulmão e edema alveolar (28/54). Corpúsculos de inclusão viral acidofílicos no epitélio de brônquios e bronquíolos e no interior de células sinciciais ocorreram em 27,8\% (15/54) dos cães afetados por cinomose. Vinte 
MORAES, F.C. et al. Diagnóstico e controle da cinomose canina. PUBVET, Londrina, V. 7, N. 14, Ed. 237, Art. 1566, Julho, 2013.

e nove dos 54 encéfalos examinados apresentavam alguma lesão microscópica. Vacuolização, principalmente, da substância branca do cerebelo e cérebro foi observada em 26 cães, sendo esta mais pronunciada no cerebelo. Alterações como gliose focal (3/54), infiltrado perivascular linfoplasmocitário (6/54), corpúsculo de inclusão principalmente intranucleares em astrócitos (7/54) malacia (5/54), meningite mononuclear (3/54) e neuronofagia (1/54) também foram observadas (SONNE, et. al., 2009).

Depleção linfóide foi observada no baço 33,3\% (17/51) dos casos examinados, em $45,7 \%$ (16/35) no timo, em 20,0\% (8/40) nas tonsilas e em $51,0 \%(26 / 51)$ nos linfonodos mesentéricos. Corpúsculos de inclusão foram observados em 3,9\% (2/51) dos casos no baço, em 7,8\% (4/51) nos linfonodos mesentéricos e $30,0 \%(12 / 40)$ nas tonsilas, presentes tanto no epitélio escamoso estratificado como no centro dos folículos linfóides. No baço havia necrose centrofolicular em 21,6\% (11/51) dos casos examinados e infiltrado histiocitário em 23,5\% (12/51), e nos linfonodos mesentéricos essas alterações foram observadas respectivamente em 11,8\% (6/51) e 27,5\% (14/51) dos casos (SONNE, et .al.,2009)

\section{DIAGNóstico difERENCIAL}

Os sintomas clínicos da cinomose canina (CC) são semelhantes aos de várias outras doenças caninas como hepatite, parvovirose, leptospirose, toxoplasmose e raiva, dificultando seu diagnóstico clínico. A cinomose também deve ser diferenciada de doenças entéricas como a pasteurelose e salmonelose, que são infecções secundárias frequentes. A traqueobronquite infecciosa canina (tosse dos canis) deve ser distinguida da forma respiratória, assim como a erliquiose canina, em que os cães podem apresentar sintomatologia respiratória e nervosa (MONTI, 2004). Sendo assim, é necessário um teste confirmatório eficaz para o diagnóstico laboratorial dessa doença (POZZA, et.al., 2007).

O diagnóstico diferencial é fundamental para a escolha do tratamento adequado, bem como para a definição do prognóstico da doença, uma vez 
MORAES, F.C. et al. Diagnóstico e controle da cinomose canina. PUBVET, Londrina, V. 7, N. 14, Ed. 237, Art. 1566, Julho, 2013.

que, quando o SNC é comprometido pelo VCC, o prognóstico é reservado, e em algumas situações a eutanásia pode ser indicada (GEBARA et al., 2004a).

Considerar também a possibilidade de intoxicação pelo chumbo ou de uma encefalomielite causada pelo Toxoplasma gondii, pois em ambos os casos pode ocorrer sinais clínicos de mioclonia, considerado característico da cinomose. A hipocalcemia também deve ser considerada como diagnóstico diferencial, pois pode gerar distúrbios do movimento que se assemelham à mioclonia (MONTI, 2004).

Em áreas epidêmicas de raiva canina, o diagnóstico diferencial desta com outras doenças que provocam sintomas semelhantes apresentam particular importância quando houver o envolvimento de seres humanos envolvidos na interação com animais suspeitos. A cinomose é uma destas enfermidades, pois provoca alterações neurológicas expressas por mioclonias, convulsões, ataxia e incoordenação motora (SILVA; MORINISHI; NUNES, 2004).

\section{TRATAMENTO}

Não há medicamentos anti-virais ou agentes quimioterápicos de valor prático para o tratamento da cinomose canina (SANTOS, 2006), tendo-se muitas vezes que optar pela eutanásia devido a progressão dos sinais neurológicos que são, em muitos casos, incompatíveis com a vida (MONTI, 2004).

Os antibióticos de amplo espectro são indicados para o controle das infecções bacterianas secundárias, além de eletrólitos, vitaminas do complexo B e complementos nutricionais, que tem como objetivo auxiliar na terapia (SANTOS, 2006).

A administração de glicocorticóides pode ser benéfica em alguns cães com doença do SNC oriunda de infecção crônica pelo VCC, mas é contra indicada em cães agudamente infectados (NELSON e COUTO, 2001). Os anticonvulsivantes também podem ser administrados, quando necessários, 
MORAES, F.C. et al. Diagnóstico e controle da cinomose canina. PUBVET, Londrina, V. 7, N. 14, Ed. 237, Art. 1566, Julho, 2013.

para o controle das convulsões. Porém, não há nenhum tratamento eficaz conhecido para as mioclonias (NELSON e COUTO, 2001).

Os cuidados de enfermagem são de extrema importância, pois aumentam as possibilidades de recuperação e a qualidade de vida do paciente, consistindo em fluidoterapia, suporte nutricional adequado, manutenção de olhos e narizes sempre limpos de descargas e constante higienização do local onde o animal é mantido (SANTOS, 2006).

A acupuntura, uma das mais antigas formas de tratamento clínico, no Oriente vem sendo usada como modalidade preventiva e terapêutica por vários milênios, e é uma expectativa terapêutica na conduta clínica da cinomose canina, principalmente para o tratamento de sequelas neurológicas que podem permanecer após o animal se recuperar da infecção pelo VCC (COLE, 1996).

\section{PROGNóstico}

O prognóstico é reservado para a maioria dos casos de cinomose aguda, especialmente na presença de sintomas neurológicos. A taxa de mortalidade varia, mas é mais alta em cães muito jovens e quando ocorre uma doença multissistêmica fulminante severa ou uma doença neurológica progressiva. Os déficits neurológicos causados pelo VCC são frequentemente irreversíveis, justificando-se a recomendação de eutanásia no caso de pacientes com sinais neurológicos progressivos severos e incapacitantes (SHERDING, 2003).

\section{MEDIDAS DE CONTROLE E PREVENÇÃO}

A vacina contra a cinomose canina é o melhor método para a redução do risco de aparecimento da enfermidade, uma vez que a ausência de vacinação pode aumentar em aproximadamente cem vezes a ocorrência da doença em cães (MARTINS; LOPES; FRANÇA, 2009).

Como a cinomose é uma doença do animal jovem, é de importância vital que a vacinação seja feita tão cedo quanto possível na vida do animal. A influência dos anticorpos maternos controla o momento em que o animal pode ser vacinado com segurança, sem que ocorra a neutralização. É geralmente 
MORAES, F.C. et al. Diagnóstico e controle da cinomose canina. PUBVET, Londrina, V. 7, N. 14, Ed. 237, Art. 1566, Julho, 2013.

aceito que com 12 semanas de idade virtualmente $100 \%$ dos filhotes perderam seus anticorpos maternos. A vacinação é, portanto, mais eficiente nessa época, mas podem existir alguns filhotes cujos anticorpos maternos diminuíram mais cedo e que estarão em risco (THOMPSON; SUTTON; CHANDLER, 1989).

A vacina contra VCC atenuada (viva modificada) é quase $100 \%$ protetora; no entanto, em cães muito jovens ou severamente doentes, estressados ou imunocomprometidos, ocasionalmente ocorre uma encefalite induzida por vacina 7-15 dias após a vacinação(SHERDING, 2003).

Falhas vacinais ocorrem, e vários fatores podem influenciá-las. As diferenças individuais de animais vacinados, como genética, idade, nutrição, estado de saúde, meio ambiente e situações de estresse, são importantes para o resultado da imunização (MONTI et al., 2007). Sendo assim, a doença clínica pode desenvolver-se, se o hospedeiro estiver imunocomprometido, infectado com o vírus antes da vacinação, tiver níveis de anticorpos maternos que suprimem a vacina ou for vacinado incompletamente (NELSON e COUTO, 2001).

Entre os fatores inerentes ao imunógeno, os principais responsáveis pelas falhas vacinais são $o$ isolado viral utilizado, a manutenção da imunogenicidade suficiente durante todo o processo de atenuação do antígeno e o número de partículas virais atenuadas em uma dose. Vacinas que foram manuseadas e estocadas indevidamente também podem resultar em falha vacinal, uma vez que as vacinas contendo vírus vivo atenuado devem ser mantidas sob refrigeração todo o tempo (MONTI et al., 2007).

A imunidade da vacinação contra cinomose é sólida e prolongada, mas não dura necessariamente a vida toda. Recomendam-se reforços de vacinação a cada 1-3 anos, dependendo do nível do risco de exposição (SHERING, 2003).

O protocolo vacinal indicado pela literatura consiste na aplicação de 3 doses vacinais no filhote, iniciando-se entre seis a oito semanas de idade, em intervalos de 21 a 31 dias e vacinações anuais como reforço, pois cães adultos podem desenvolver a doença (MONTI, 2004), uma vez que o título de 
MORAES, F.C. et al. Diagnóstico e controle da cinomose canina. PUBVET, Londrina, V. 7, N. 14, Ed. 237, Art. 1566, Julho, 2013.

anticorpos terá declinado a níveis não protetores em até um terço dos cães (SANTOS, 2006).

A administração de vacinas vivas modificadas contra o VCC deve ser adiada em cães que estejam com sinais clínicos de doença compatível com infecção pelo parvovírus (NELSON e COUTO, 2001).

Monti (2004) observou que cães que são vacinados em lojas que comercializam produtos agropecuários e que geralmente não contam com a orientação de um médico veterinário, apresentam maior frequência da doença, quando comparados aos cães vacinados em clínicas veterinárias, demonstrando a importância de realizar as vacinações em locais idóneos e com a presença de um profissional capacitado.

Importante levar em consideração que as primeiras vacinas de vírus vivos atenuados que reduziram drasticamente o impacto da infecção na população canina pelo VCC surgiram há mais de 50 anos. Desde então, utilizase a mesma vacina na proteção de cães em todo o mundo (POZZA et.al., 2007). Esse é um fator importante a se considerar sobre o vírus da cinomose canina, pois ele possui uma diversidade genética, o que pode causar a redução do valor protetor de vacinas feitas com cepas antigas. Outro item a ser considerado é que a existência de novas variantes virais abre caminho para a expansão do VCC para novos hospedeiros, questionando assim, a eficácia das vacinas atuais (MARTINS; LOPES; FRANÇA, 2009).

Sendo assim, um aumento da vigilância epidemiológica é indispensável para identificação de novas variantes do VCC e, consequentemente fabricação de vacinas mais eficazes, com intuito de evitar surtos da doença (MARTINS; LOPES; FRANÇA, 2009)

Os cães em fase de viremia devem ser mantidos isolados dos demais animais de convívio para evitar a contaminação pelo contato com as secreções e excreções. Além disso, o uso rotineiro de desinfetantes no ambiente é de extrema importância, sabendo que o vírus é inativado pelo formol a 0,5\%, fenol a $0,75 \%$ e pelos desinfetantes à base de amônia quaternária a 0,3\% (SANTOS, 2006). 
MORAES, F.C. et al. Diagnóstico e controle da cinomose canina. PUBVET, Londrina, V. 7, N. 14, Ed. 237, Art. 1566, Julho, 2013.

Nenhum risco à saúde pública é associado com o vírus da cinomose (NELSON e COUTO, 2001), uma vez que não há evidência definitiva da infecção obtida naturalmente pelo VCC em seres humanos. Entretanto, infecção experimental assintomática já foi descrita. Recentemente, tem-se sugerido que algumas doenças neuroendócrinas dos ser os humanos possam estar relacionadas a infecções pelo VCC, tais como a esclerose múltipla e a panencefalite esclerosante subaguda (MARTINS; LOPES; FRANÇA, 2009).

\section{CONCLUSÃO}

A cinomose é uma doença infecciosa que deve ser tratada com grande responsabilidade, pois acomete o sistema nervoso dos animais, podendo causar a morte ou gerar déficits irreparáveis que comprometerão a vida do animal para sempre. No Brasil ainda ocorre com frequência devido a falhas em seu controle e a falta de instruções e esclarecimento da população sobre a etiologia e epidemiologia do vírus. Métodos preventivos como isolamento do animal enfermo e desinfecção das instalações com desinfetantes apropriados, fazem parte de um controle efetivo para se evitar a disseminação das partículas virais.

Vários animais podem ser afetados, porém, como o cão é o reservatório mais importante (atuando como principal fonte de infecção), o controle nessa espécie animal, por meio de vacinação é necessário. A maior contribuição que os médicos veterinários podem oferecer para que isso ocorra, além de indicar, conservar e administrar a vacina de forma correta é transmitindo seus conhecimentos pela prática de educação em saúde, disseminando informações que auxiliarão na não ocorrência desta doença em nosso país.

\section{REFERÊNCIAS BIBLIOGRÁFICAS}

APPEL, M. J. G.; YATES, R. A.; FOLEY, G.L.; BERNSTEIN, J.J; SANTINELLI, S.; SPELMAN, L.H.; MILLER, L.D.; ARP, L.H.; ANDERSON, M.; BARR, M.; PEARCE-KELLING, S.; SUMMERS, A. Canine distemper epizootic in lions, tigers, and leopards in North America. Journal of Veterinary Diagnostic Investigation, p. 277-288, 1994. 
BARBOSA, J. M; PASSOS, R. F. B. Análises dos casos de cinomose H.V. São Francisco de Assis na Faculdade Latino americana - Anápolis-GO. In: Ensaios e ciências: Ciências Biológicas, agrárias e da saúde. v.12, n.01, p. 139-150, nov. 2008.

BORBA, T. R.; MANNINGEL, R. C.; FRAPORTI, C. K.; HEADLEY, S. A.; SAITO, T. B. Cinomose: Dados epidemiológicos Maringá-RP (1998-2001). In: Iniciação Cientifica. v. 04, n. 01, p. 5356. Mar./Jul. 2002.

BRAZ, G. F. Padronização e teste da técnica de imunofluorescência direta para o diagnóstico da cinomose canina, 2009. 43 f. Dissertação (mestrado) - Universidade Federal de Minas Gerais, Escola de Veterinária, 2009.

COLE, E. F. Avaliação dos efeitos terapêuticos obtidos com a alopatia e acupuntura no tratamento de distúrbios neurológicos decorrentes da cinomose canina, 1996. $204 \mathrm{f}$. Dissertação (Mestrado) - Curso de Medicina Veterinária, Universidade Federal Rural de Pernambuco, Recife, 1996.

DIAS-CATÃO, J. L. Biossegurança na manipulação de animais silvestres. Ciência Veterinária nos Trópicos, v. 11, p.178-181, 2008.

GAMA, F.G.V. NISHIMORI, C.T.; SOBREIRA, M.R. Evaluation of electrophoretic profile and albumin quota in the cerebrospinal fluid of dogs with distemper showing or not neurvous signs.

Arquivo Brasileiro de Medicina Veterinária e Zootecnia, v. 59, n.1, p.77-80, 2007.

GAMA, F. G. V.; NISHIMORI, C. T.; SOBREIRA, M. R.; SANTANA, A. E. Caracteres físicoquinicos e citológicos do liquor de cães em diferentes fases da cinomose. In: Ciência Rural, Santa Maria, v. 35, n. 3, p. 596-601, mai./jun., 2005.

GEBARA, C. M. S.; WOSIACKI, S. R.; NEGRÃO, F. J.; ALFIERI, A. A.; ALFIERI, A. F. Lesões histológicas no sistema nervoso central de cães com encefalite e diagnostico molecular da infecção pelo vírus da cinomose canina. In: Arquivo Brasileiro de Medicina Veterinária e Zootecnia, Belo Horizonte - MG, v.56, n.2, p.168-174, 2004a.

GEBARA, C. M. S.; WOSIACKI, S. R.; NEGRÃO, F. J.; OLIVEIRA, D. B.; BELONI, S. N. E. ALFIERI, A. A.; ALFIERI, A. F. Detecção do gene da nucleoproteína do vírus da cinomose canina po RT-PCR em urina de cães com sinais clínicos de cinomose. In: Arquivo Brasileiro de Medicina Veterinária e Zootecnia, v.56, n.4, p. 480-487, fev. 2004b.

GRÖNE, A.; FONFARA, S.; BAUMGÄRTNER, W. Cell Type-Dependent Cytokine Expression after Canine Distemper Virus Infection. Viral Immunology,v.15, n. 3,p.493-505.

HOSKINS, J. D. Doenças Virais Caninas. In: ETTINGER, S. J.; FELDMAN, E. C. Tratado de medicina interna veterinária - Doenças do cão e do gato. 5. ed. São Paulo: Guanabara Koogan, 2004. v. 2, p.440-445.

LITFALLA, F.; HAMZÉ, A. L.; PACHECO, A. M.; SOUZA, C. C.; RODRIGUES, C. A. L. S.; FILADELPHO, A. L.; BARIANI, M. H. Cinomose e o processo de desmielinização. In: Revista Científica Eletrônica de Medicina Veterinária, Garças-SP, n. 11, jul. 2008.

MAIA, O.B.; GOUVEIA, A.M.G.; SOUZA, A.M.; BARBOSA, E.F. Avaliação pós-vacinal de lobos guarás Chrysocyon brachyurus (Illiger, 1811) contra os vírus da cinomose e parvovirose caninas. Arquivo Brasileiro de Medicina Veterinária e Zootecnia, v. 51, n.5, 1999.

MARTINS, D. B.; LOPES, S. T. D. A.; FRANÇA, R. T. Cinomose canina: Revisão de literatura. Acta Veterinaria Brasilica, v.3, n.2, p.68-76, 2009. 
MELlO, F. C.; AMARAI, G. A. C.; RODRIGUeS, C. F. M.; PINTO, E. A. T.; Lot, R. F. E. Aspectos clinicopatológicos da cinomose em cães. In: Revista cientifica eletrônica de Medicina Veterinária, Garça - SP, Jan. 2008.

MONTI, F. S. Anticorpos contra o vírus da cinomose em cães vacinados em diferentes estabelecimentos da área urbana do município de Viçosa/MG. 2004. Tese (Mestrado em Medicina Veterinária) - Universidade Federal de Viçosa, Minas Gerais.

NEGRÃO, F.J.; WOSIACKI, S. H.; ALFIERI, A.A; ALFIERI, A.F. Perfil de restrição de um fragmento do gene da hemaglutinina amplificado pela RT-PCR a partir de estirpes vacinais e selvagens do vírus da cinomose canina. Arquivo Brasileiro de Medicina Veterinária e Zootecnia, v.58, n.6, p.1099-1106, 2006.

NEGRÃO, F.J.; ALFIERI, A.A.; ALFIERI, A. F. Avaliação da urina e leucócitos como amostras biológicas para a deteç̧ão ante mortem do vírus da cinomose canina por RT-PCR em cães naturalmente infectado. In: Arquivo Brasileiro de Medicina Veterinária e Zootecnia. Belo Horizonte, v.59, n.1, fev. 2007.

NELSON, R. W.; COUTO, C.G. Medicina Interna de Pequenos Animais. 2. Ed. Rio de Janeiro: Guanabara Koogan, 2001. p.1012-1014.

OLIVEIRA, A. C.; ANTÔNIO, N. S.; ZAPPA, V. Cinomose canina - Relato de caso. In: Revista cientifica eletrônica de Medicina Veterinária, Garça - SP, Jan. 2009.

ORSINI, H.; BONDAN, E. F. Patogenia das lesões do sistema nervoso central (SNC) na cinomose canina. Clínica Veterinária: Revista de educação continuada do clínico veterinário de pequenos animais, São Paulo, n.74 , p.28-31, 2008.

POZZA, M.; SIMONETTI, A.B.; ESTEVES, P.A.; RIJSEWIJK, F.A.M.; ROEHE, P.M.Detecção do vírus da cinomose canina por RT-PCR utilizando-se oligonucleotídeos para os genes da fosfoproteína, hemaglutinina e neuraminidase. Arquivo Brasileiro de Medicina Veterinária e Zootecnia, v.59, n.5, p.1154-1162, 2007.

QUINN, P. J.; MARKEY, B.K.; CARTER, M.E.; DONNELLY, W.J.; LEONARD, F.C. Microbiologia Veterinária e Doenças Infecciosas. Porto Alegre: Artmed, 2005.

REZENDE, R. S.; COELHO, H.E.; KAMIMURA, R.; SEVERINO, R. S.; OLIVEIRA, P. C.L.; MEDEIROS, A.A.; MAGALHÃES, A.O.C. Análise microscópica do miocárdio ventricular esquerdo em cães soropositivos para cinomose. Pesquisa Veterinária Brasileira, p.117-119, 2009.

SANTOS, B. M. Cinomose Canina - Revisão de literatura. 2006. Trabalho monográfico (Pós-graduação "lato sensu" em clínica medica e cirurgica de pequenos animais) Universidade Castelo Branco. Goiânia-GO.

SHERING, R.G. Cinomose. In: SHERING, R.G. Manual Sanders: Clínica de Pequenos Aminais. São Paulo: Roca Ltda, 2003. Cap. 11, p. 117-120.

SILVA, L.H. Queiroz da; MORINISHI, C.K.; NUNES, C.M. Diagnóstico diferencial entre a raiva e a cinomose canina em amostras de cérebro de cães examinadas no período de 1998 a 2001 na região de araçatuba, sp, Brasil. Arquivos do Instituto Biológico, v.71, n.3, p.317-321, 2004.

SILVA, M. C.; FIGHERA, R. A.; MAZZANTI, A.; Brum, J.S.; PIEREZAN, F.; BARROS, C.S.L. Neuropatologia da cinomose canina: 70 casos (2005-2008). Pesquisa Veterinária Brasileira, p. 643-652, 2009. 
SONNE, L. Achados patológicos e imunoistoquímicos de cães infectados pelo vírus da cinomose canina. 2008. Tese (Mestrado em Ciências Veterinárias) - Universidade Federal do Rio Grande do Sul, Porto Alegre.

SONNE, L.; OLIVEIRA, E.C.; PESCADOR, C.A.; SANTOS, A.S.; PAVARINI, S.P.; CARISSIMI, A.S.; DRIEMEIER, D. Achados patológicos e imuno-histoquímicos em cães infectados naturalmente pelo vírus da cinomose canina. Pesquisa Veterinária Brasileira, p.143-149, 2009.

THOMPSON, D.J.; SUTTON, J.B.; CHANDLER, E.A. Medicina Terapêutica de Caninos. São Paulo: Manole Ltda, Cap. 13, p. 387- 392, 1989. 